\title{
Experimental Study of Particle Collection Efficiency of Cylindrical Inlet Type Cyclone Separator
}

\author{
G. B. Sakura and Andrew Y. T. Leung
}

\begin{abstract}
The performance of collection efficiency of cylindrical inlet-type cyclone separator for relatively low solid loading rate conditions is reported. Cyclone separators usually operate under high solid loading conditions, but the demand of air pollution control at outdoor densely polluting activities as construction sites and application of power generators, it is advantageous to use cyclone separators to control outdoor air pollution by cyclone separators. Grade efficiencies and overall collection efficiencies have been investigated from $0.008 \mathrm{~g} / \mathrm{m}^{3}$ to $0.2 \mathrm{~g} / \mathrm{m}^{3}$ solid loading rates at $5 \mathrm{~m} / \mathrm{s}$ and $10 \mathrm{~m} / \mathrm{s}$ inlet velocity conditions. Experimental data were compared with two theoretical predictions based on empirical and mechanistic relationships, developed by Smolik and Muschelknautz. To achieve a better understanding of particle separation efficiency, particle cut size diameter for selected loading rate were considered with theoretical approached by Muschelknautz model. Both experimental and theoretical results showed that with the increase of solid loading rate and inlet velocity, the particle collection efficiency of cyclone separator increases.
\end{abstract}

Index Terms - Cut size diameter, cyclone separator, grade efficiency, solid loading rate, swirling flow, overall collection efficiency.

\section{NOTATION}

$B$

$C_{1}$

$C_{2}$

$D$

$D_{50}$

$D_{e}$

$D_{i}$

$D_{o}$

$H$

$H_{c o} \quad$ cyclone conical body height

$H_{c y} \quad$ cyclone cylindrical body height

$H_{h} \quad$ cyclone hopper height

$m_{h} \quad$ solid mass collected in hopper

$m_{\text {in }} \quad$ total inlet mass

$x_{\text {fact }}$ modification factor of cut size diameter ( by

Muschelknautz)

$\eta\left(C_{1}\right)$ given efficiency

$\eta\left(C_{2}\right)$ calculated efficiency

$\eta_{\text {overall }}$ overall collection efficiency

\section{INTRODUCTION}

Cyclone separators are extensively used for a particle

Manuscript received April 4, 2014; revised June 4, 2014.

G. B. Sakura and Andrew Y. T. Leung are with the Department of Civil and Architectural Engineering, City University of Hong Kong, Tat Chee Avenue, Kowloon Tong, Hong Kong SAR, China (e-mail: sganegama2-c@ my.cityu.edu.hk, bcleung@cityu.edu.hk). controlling industries as, air pollution control, aerosol sampling and particulate matter control, due to their simplicity of design, inexpensive manufacturing cost, ease in maintenance and adaptability to a wide range of operating conditions [1]. Despite of simplicity and other operational advantages, well designed cyclone separators can be efficiently remove particles larger than 2 micrometer in size [2].

Cyclone separators can be classified according to their body shape, inlet configuration, and inlet/outlet flow direction [3]. Most popular cyclone separator type is reversed flow type which consists of a slot type inlet and a conical-body (cylinder-on-cone). Relevant to the literature, many studies (e.g., [4] and [5]) have been performed theoretical, experimental and lately computational fluid dynamic (CFD) simulations to understand the performance of slot type inlet cyclone separators by considering geometry and operational conditions. These researches were also involved to develop design parameters and relationships in order to improve and estimate collection efficiency. To increase the performance of cyclone separator, knowledge based on effect of particle solid loading rate is one of main parameter for any type of cyclone design.

Earliest study [6], have been stated that, there could be a small increment of collection efficiency with the increase of solid loading under the assumption of coarser particles carry finer particles to cyclone wall region. But a survey of experimental results from literature considering a loading range of 2.3 to $228.8 \mathrm{~g} / \mathrm{m}^{3}$, has showed a increase of collection efficiency with the increase of solid loading rate [7] (as reported by [8]). For coarse range particle application is observed the same behavior for particle loading rate up to $100 \mathrm{~g} / \mathrm{m}^{3}$ [9]. Similar observation is also reported by [10] for particle loading rates up to $235.2 \mathrm{~g} / \mathrm{m}^{3}$, conducted under different inlet velocity and temperature conditions. This study further observed an increment of the collection efficiency with increase of temperature. Rising solid loading rate from $4.98 \mathrm{~g} / \mathrm{m}^{3}$ to $130.8 \mathrm{~g} / \mathrm{m}^{3}$ at three different inlet velocity conditions, noticed a dramatic increment of overall collection efficiency at low velocity conditions [11], [12]. Considering extremely low particle loading rates, from $5 \mathrm{mg}$ to $20000 \mathrm{mg}$, overall and grade efficiency curves were studied by [8], for small scale cyclone separators and observed a similar increment behavior for low to high inlet velocity conditions. In addition, this study indicated that at low solid loading conditions, particle agglomeration is significant in particle separation. Although many of literature show a increase of overall collection efficiency with increase of solid loading rate, a reduction of collection efficiency by solid loading rate increment from $1.69 \mathrm{~g} / \mathrm{m}^{3}$ to $6.72 \mathrm{~g} / \mathrm{m}^{3}$ was observed by [13]. Similar trend was observed for the study 
[14] which considered high solid loading conditions $(0.84$ $\mathrm{kg} / \mathrm{m}^{3}-24.6 \mathrm{~kg} / \mathrm{m}^{3}$ ) and results showed that the collection efficiency increases up to a certain maxima and then starts to decrease.

An unchangeable behavior of grade efficiency curves by changing the solid loading rate, although overall efficiency increased was investigated by [15]. Numerical simulations conducted by [16]-[18], clearly described the decrease of swirling capacity of the turbulent flow inside the cyclone separator with the solid loading. Contradiction to experimental studies by [10], numerical investigations conducted by [18] has been reported a weaken of collection efficiency with increase of temperature.

Although many researchers have been employed to understand the characteristics of efficiency of cyclone separators most of them were considered relatively higher loading rates. But cyclone separators can be applied to low solid loading rates too. Hence, the behavior of collection efficiency with low solid loading rate has been studied in present study. While there are many investigations related to slot type cyclone separators, no studies found in literature based on cylindrical inlet type cyclone separators which are also used in industrial applications. Therefore, present study focus on particle loading rate effect on collection efficiency of cyclone separator for an industrially use cylindrical inlet type cyclone separator.

\section{EXPERIMENT}

The geometric parameters of studied cyclone separator are given in Fig. 1 and Table I. Generally, there are standard ratios for cyclone separator geometry, with respect to the cyclone body diameter for slot type cyclone separators by the literature. But the cylindrical inlet cyclone separator used in this study was an industrial cyclone separator without such a specific ratio dependency with body diameter.

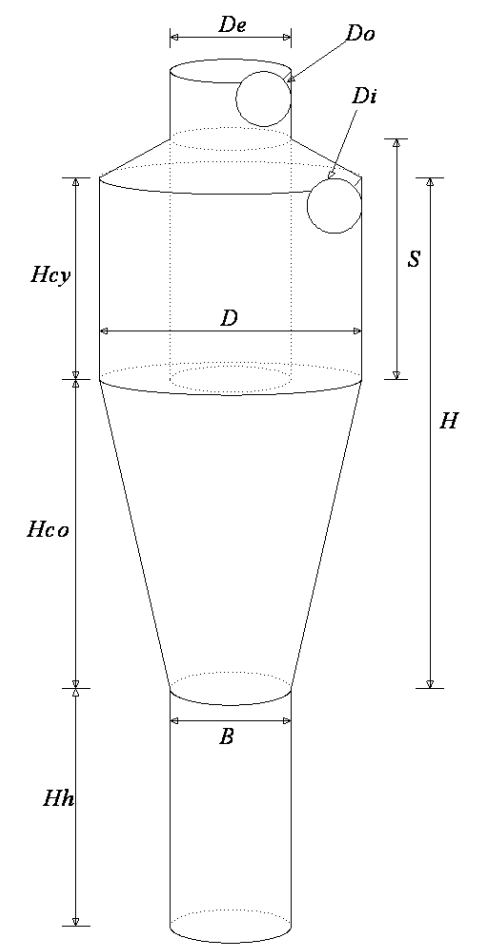

Fig. 1. Geometry of the cyclone separator.
TABLE I: DIMENSIONS OF THE CYCLONE SEPARATOR

\begin{tabular}{cc}
\hline \hline Geometric parameter & Dimension (mm) \\
\hline Body diameter & 330.200 \\
Inlet and outlet pipe diameters & 69.120 \\
Cyclone cylindrical height & 254.000 \\
Cyclone total height & 693.7375 \\
Vortex finder height & 303.2125 \\
Vortex finder diameter & 152.400 \\
Hopper height & 254.000 \\
Cone tip/Hopper diameter & 152.400 \\
\hline \hline
\end{tabular}

The experiments were performed for two inlet velocity conditions, $5 \mathrm{~m} / \mathrm{s}$ and $10 \mathrm{~m} / \mathrm{s}$. The air flow was generated by using a vacuum at the cyclone separator outlet. The vacuum was consisted with a bag filter to arrest particles in the exit air flow. Particle laden air was entered into cyclone separator through an extended inlet of $800 \mathrm{~mm}$ of length to verify a fully developed flow at the real entrance of cyclone separator. Arizona Test dust (Powder Technology, INC), having density of $2650 \mathrm{~kg} / \mathrm{m}^{3}$ was used as solid phase. The particle size distribution of test dust was $0.742-18$ micrometer with a standard deviation of 1.762 micrometer. Particles were introduced to air flow at the entrance of extended inlet to achieve a well mixed particle laden flow.

The collected solid mass by the cyclone separator was measured by weighting the solid mass collected to the bottom hopper. To get the fractional efficiency curves, Fluke particle counter (Fluke 983, FLUKE Inc.) was used. For the higher solid concentrations, Fluke particle counter was not capable to measure. So that two volumes of flow extracted from the inlet and outlet by using $1 \mathrm{~mm}$ inlet diameter sampling probes and suction tubes (VRL 50-080108, Nihon Pisco), under the pressure of $100 \mathrm{kPa}$ and extracted flows were diluted by supplying additional air by air blowers. It is assumed that the particle concentrations of extracted volumes were proportional to particle concentrations of inlet and outlet air flows. Each experiment was conducted for $15 \mathrm{~min}$. overall and fractional efficiencies for particle loading rates of 0.008 $0.2 \mathrm{~g} / \mathrm{m}^{3}$ were measured for two considered inlet velocity conditions.

\section{RESUlTS}

The overall collection efficiency is defined as, in a time interval the ratio between the mass of solids collected by the cyclone and the mass flow rate of incoming solids as indicated in (1).

$$
\eta_{\text {overall }}=\frac{m_{h}}{m_{\text {in }}}
$$

Measured overall collection efficiencies for the cylindrical type inlet cyclone separator are shown in Fig. 2. It is clearly pictured the significance of inlet velocity on overall collection efficiency. The increase of inlet velocity directs to higher collection efficiency, regardless of solid loading rate. 
The consequence of increasing solid loading rate to collection efficiency indicates that overall collection efficiency increases with the raise of solid loading.

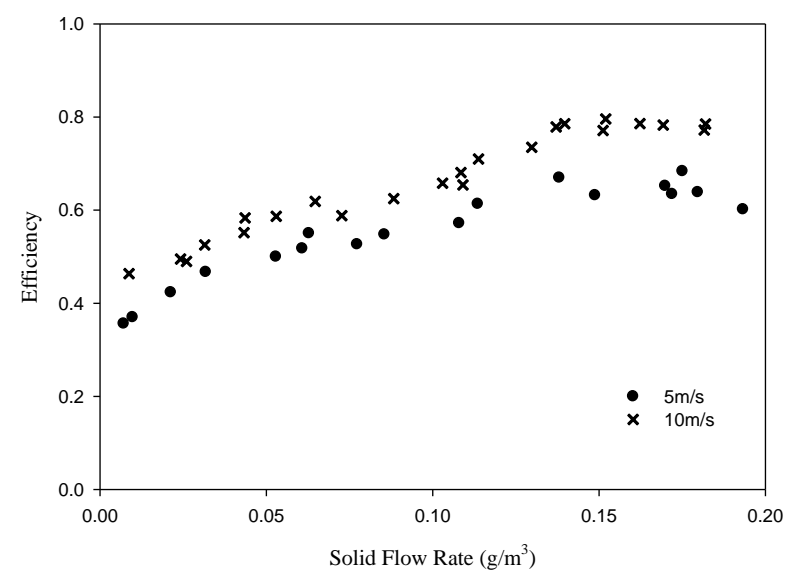

Fig. 2. Experimental overall efficiencies of two inlet velocity conditions.

To obtain grade efficiency curves, percentage of efficiency relates to a given particle diameter was considered. Relevant to measuring number concentrations of particles by Fluke 983, the deviation of each particle channel is quite larger, so for all observations, relevant particle size channels were considered other than assuming specific particle diameters. For selected solid loading rates, grade efficiency curves are shown in Fig. 3. Grade efficiency curves are important to determine the cut size diameter, $D_{50}$ of the cyclone separator, which is defined as particle size having a $50 \%$ of collection efficiency and all particles having larger diameters than this value will be collected with a fraction of above $50 \%$. From Fig. 3, it can be seen that the collection fractions of larger particles are higher than smaller and also noticeable, at low velocity conditions, the collection efficiency of larger particles also shows low collection efficiency.

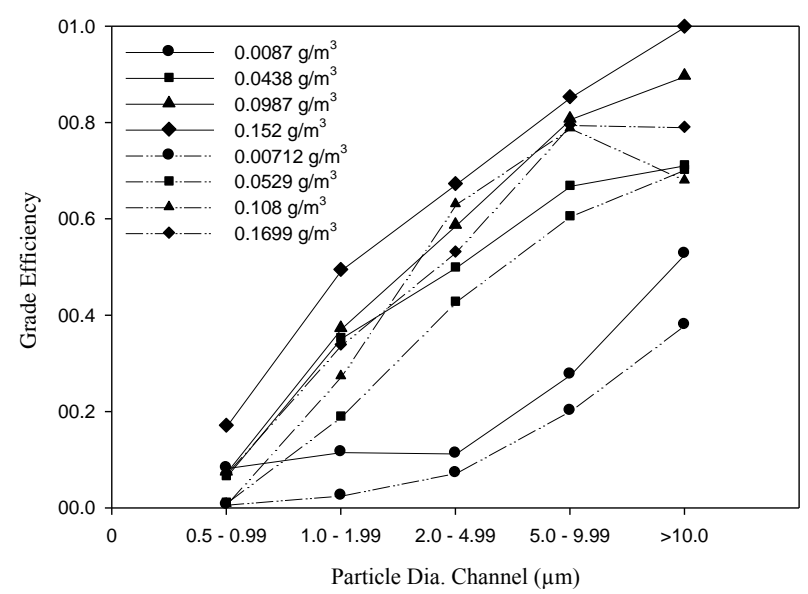

Fig. 3. Grade efficiency curves for selected solid loading conditions (bold line for $10 \mathrm{~m} / \mathrm{s}$ velocity and dash line for $5 \mathrm{~m} / \mathrm{s}$ velocity).

The theoretical predictions of cyclone separator efficiency can be compared with experimental observations to get a better knowledge of relationships between theories and experiments. There are many theoretical approaches to predict cyclone separator efficiency (e.g., [4], [19]), but most of them have not deemed about the influence of solid loading rate except by two empirical models were proposed by Smolik (quoted by Svarovsky [20]) and Zenz [21] respectively, which were developed based on knowledge of experimental results. Graphical relationship proposed by Zenz cannot be applied in this study as it can only predict collection efficiencies for solid loading concentrations larger than $2.29 \mathrm{~g} / \mathrm{m}^{3}$.

The empirical relationship shown in (2) which was developed by Smolik, predicts overall collection efficiencies for any given particle loading rate with respect to a known particle loading rate and collection efficiency.

$$
\eta\left(C_{2}\right)=1-\left[1-\eta\left(C_{1}\right)\right]\left(\frac{C_{1}}{C_{2}}\right)^{1.8}
$$

The predictions by Smolik empirical relationship with experiment results are shown in Fig. 4. To generate Smolik prediction curves, experimental results for $0.1 \mathrm{~g} / \mathrm{m}^{3}$ were used as known solid concentration and efficiency. Fig. 4 demonstrates that Smolik method under predicts the cyclone efficiency for larger solid concentrations than known value for initial concentration but over predicts efficiency smaller than known initial value. But for lower solid loadings than $0.1 \mathrm{~g} / \mathrm{m}^{3}$ in $5 \mathrm{~m} / \mathrm{s}$ velocity condition, Smolik prediction is well agreed with the experimental data.

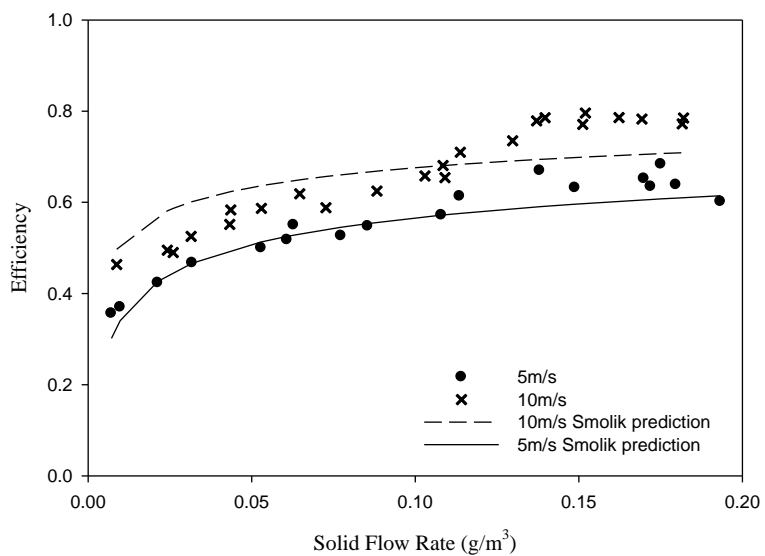

Fig. 4. Experimental overall collection efficiencies with the theoretical prediction curves by Smolik method.

Muschelknautz [22], [23] proposed a mechanistic analysis to predict both cut size diameter and overall collection efficiency of a given cyclone separator. This method is also used to predict collection efficiencies in present study and graphical views of grade efficiency curves for two velocity conditions are shown in Fig. 5 and Fig. 6. Even though theoretical predictions show in particle size channel basis, for calculations of Muschelknautz model, mean values of each particle channel was considered. To obtain well matched data with theory and experimental, the modification factor $\left(x_{f a c t}\right)$ for cut size diameter defined in this model was mismatched with experimental values. Value for $x_{\text {fact }}$ is normally falls in to the range of $0.9-1.4$ according to Muschelknautz model. But in present study, it was considered in a range of 0.16-0.9. This contradiction may be due to the assumptions of collection efficiency. In Muschelknautz model assumed collection efficiency ranged 
in $90 \%-99 \%$, though this study has overall collection efficiencies which are generally less than $90 \%$.

Generally, theoretical predictions by Muschelknautz model are underestimated the grade efficiency values for larger solid loading conditions and for extremely low loading condition the predictions were agreed with experimental investigations. Moreover, Muschelknautz model shows a "S"-shape pattern for grade efficiency curves, which is not similar to the pattern in experimental calculations, but the general increment trend is similar.

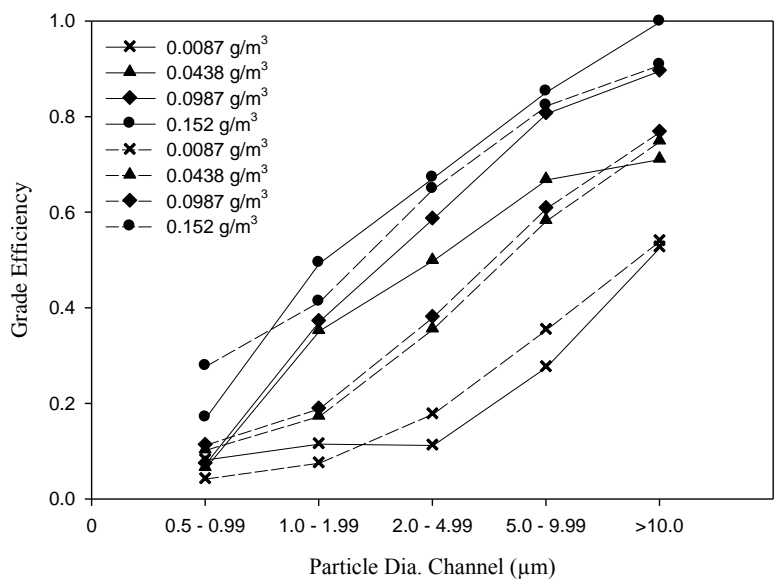

Fig. 5. Experimental and theoretical grade efficiency curves for different solid loading rates at $10 \mathrm{~m} / \mathrm{s}$ velocity (bold line for experimental values and dash line for theoretical predictions).

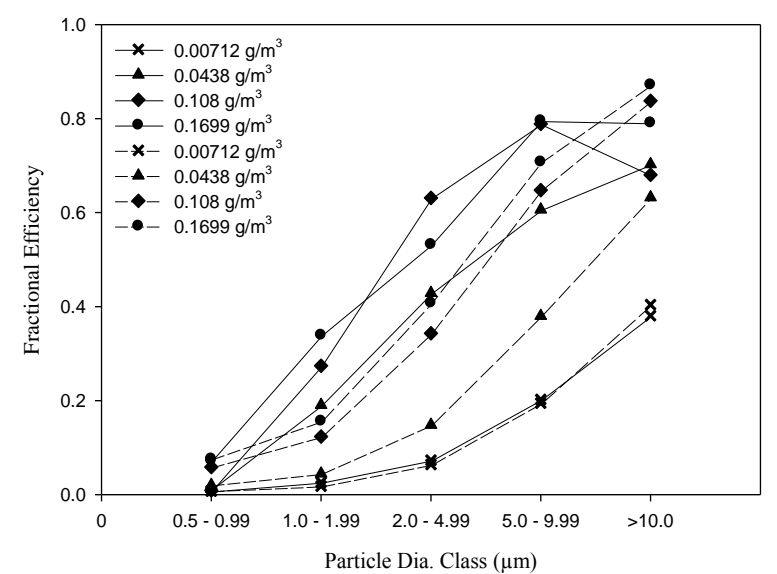

Fig. 6. Experimental and theoretical grade efficiency curves for different solid loading rates at $5 \mathrm{~m} / \mathrm{s}$ velocity (bold line for experimental values and dash line for theoretical predictions).

TABLE II: A COMPARISON OF PARTICLE CUT SIZE DIAMETERS BETWEeN EXPERIMENTAL AND MODEL PREDICTIONS

\begin{tabular}{cccc}
\hline \hline $\begin{array}{c}\text { Velocity } \\
(\mathrm{m} / \mathrm{s})\end{array}$ & $\begin{array}{c}\text { Flow Rare } \\
\left(\mathrm{g} / \mathrm{m}^{3}\right)\end{array}$ & Experiment & Muschelknautz \\
\hline 10 & 0.0087 & $>10$ & 11.840 \\
& 0.0438 & $2.0-4.99$ & 5.330 \\
& 0.0987 & $2.0-4.99$ & 4.860 \\
& 0.152 & $1.0-1.99$ & 1.900 \\
\hline 5 & 0.0071 & $>10$ & 17.430 \\
& 0.0529 & $5.0-9.99$ & 9.690 \\
& 0.1080 & $2.0-4.99$ & 4.849 \\
& 0.1699 & $2.0-4.99$ & 4.075 \\
\hline \hline
\end{tabular}

Table II shows the theoretical and experimental cut size diameter, $D_{50}$ for considered flow rates.
It is shown that for low mass loading conditions, experimental and Muschelknautz model predictions are well matches, but for higher solid loading rate $\left(0.152 \mathrm{~g} / \mathrm{m}^{3}\right.$ at $10 \mathrm{~m} / \mathrm{s}$ inlet velocity and $0.1080 \mathrm{~g} / \mathrm{m}^{3}$ and $0.1699 \mathrm{~g} / \mathrm{m}^{3}$ at $5 \mathrm{~m} / \mathrm{s}$ inlet velocity), this model over predicts the overall collection efficiency.

Due to data visualization is shown by particle size channels in experiment, it is difficult to conclude about cut size diameter by theory. But considering particle size channels, theoretical values are fallen in to same particle channels.

Overall collection efficiencies by Muschelknautz model comparing with experimental values are shown in Table III.

TABLE III: A COMPARISON OF OVERALL COLLECTION EFFICIENCY BETWEEN EXPERIMENTAL AND MODEL PREDICTIONS

\begin{tabular}{cccc}
\hline $\begin{array}{c}\text { Velocity } \\
(\mathrm{m} / \mathrm{s})\end{array}$ & $\begin{array}{c}\text { Flow Rare } \\
\left(\mathrm{g} / \mathrm{m}^{3}\right)\end{array}$ & Experiment & Muschelknautz \\
\hline 10 & 0.0087 & 0.4637 & 0.4918 \\
& 0.0438 & 0.5833 & 0.7006 \\
& 0.0987 & 0.6750 & 0.6745 \\
& 0.152 & 0.7960 & 0.8851 \\
\hline 5 & 0.0071 & 0.3561 & 0.3646 \\
& 0.0529 & 0.5000 & 0.5693 \\
& 0.1080 & 0.5718 & 0.7895 \\
& 0.1699 & 0.6519 & 0.8305 \\
\hline \hline
\end{tabular}

\section{CONCLUSION}

The collection efficiency under low particle loading rates has been investigated in present study for cylindrical inlet type cyclone separator. Generally, incremental behavior of collection efficiency with solid loading rate was pictured in all cases. The study will be extended to investigate particle loading effects at higher loading rates and the effects of extended hopper tube for the collection efficiency.

\section{REFERENCES}

[1] K. Lim, H. Kim, and K. Lee, "Characteristics of the collection efficiency for a cyclone with different vortex finder shapes," Journal of Aerosol Science, vol. 35, pp. 743-754, 2004.

[2] W. L. Heumann, "Cyclones," Industrial Air Pollution Control Systems, New York: McGraw-Hill, 1997, pp. 305-368.

[3] A. C. Hoffmann and L. E. Stein, Gas Cyclones and Swirl Tubes, Springer, 2002.

[4] W. Barth, "Design and layout of the cyclone separator on the basis of new investigations," Brennstoff-Warme-Kraft, vol. 8, pp. 1-9, 1956.

[5] C. J. Stairmand, "The design and performance of cyclone separators," Trans. Inst. Chem. Eng., vol. 29, pp. 356-383, 1951

[6] A. J. T. Linden, "Investigations into cyclone dust collectors," in Proc. the Institution of Mechanical Engineers, vol. 160, pp. 233-251, 1949.

[7] A. Stem, K. Caplan, and P. Bush, "Cyclone dust collectors: Engineering report," Division of Refining, American Petroleum Institute, New York, vol. 67, 1955.

[8] Z. Ji, Z. Xiong, X. Wu, H. Chen, and H. Wu, "Experimental investigations on a cyclone separator performance at an extremely low particle concentration," Powder Technology, vol. 191, pp. 254-259, 2009.

[9] Y. Mori, A. Suganuma, and S. Tanaka, "On collection efficiency of gas cyclone in coarse particle range," Journal of Chemical Engineering of Japan, vol. 1, pp. 82-86, 1968.

[10] P. Patterson and R. Munz, "Cyclone collection efficiencies at very high temperatures," The Canadian Journal of Chemical Engineering, vol. 67, pp. 321-328, 1989.

[11] A. Hoffmann, H. Arends, and H. Sie, "An experimental investigation elucidating the nature of the effect of solids loading on cyclone performance," Filtration \& separation, vol. 28, pp. 188-193, 1991. 
[12] A. C. Hoffmann, A. Van Santen, R. Allen, and R. Clift, "Effects of geometry and solid loading on the performance of gas cyclones," Powder Technology, vol. 70, pp. 83-91, 1992.

[13] K. Tuzla and J. Chen, "Performance of a cyclone under high solid loadings," AIChE Symposium Series, 1992, pp. 130-130.

[14] F. L. Fassani and L. Goldstein Jr., "A study of the effect of high inlet solids loading on a cyclone separator pressure drop and collection efficiency," Powder Technology, vol. 107, pp. 60-65, 2000.

[15] H. Mothes and F. Löffler, "Prediction of particle removal in cyclone separators," Int. Chem. Eng, vol. 28, pp. 231-240, 1988

[16] J. Derksen, S. Sundaresan, and H. Van Den Akker, "Simulation of mass-loading effects in gas-solid cyclone separators," Powder Technology, vol. 163, pp. 59-68, 2006.

[17] F. Qian, Z. Huang, G. Chen, and M. Zhang, "Numerical study of the separation characteristics in a cyclone of different inlet particle concentrations," Computers \& Chemical Engineering, vol. 31, pp. 1111-1122, 2007.

[18] X. Xue, G. Sun, G. Wan, and M. Shi, "Numerical simulation of particle concentration in a gas cyclone separator," Petroleum Science, vol. 4, pp. 76-83, 2007.

[19] C. E. Lapple, "Gravity and Centrifugal Separation," American Industrial Hygiene Association Quarterly, vol. 11, pp. 40-48, 1950.

[20] L. Svarovsky, "Economics of gas cleaning; equipment selection," in Handbook of Powder Technology. vol. 3, J. C. Willams and T. Allen, Eds. Amsterdam: Elsevier Scientific Publishing Company, 1981.

[21] F. Zenz, "Cyclone separators," Manual on Disposal of Refinery Wastes; Volume on Atmospheric Emissions, API Publications, 1975.

[22] E. Muschelknautz, "Die berechnung von zyklonabscheidern für gase," Chemie Ingenieur Technik, vol. 44, pp. 63-71, 1972.

[23] E. Muschelknautz and W. Krambrock, "Design of cyclone separators in the engineering practice," Staub-Reinhalt. Luft, vol. 30, pp. 1-12, 1970.

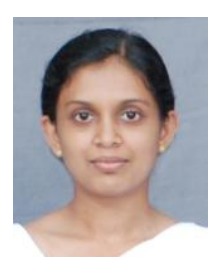

G. B. Sakura has received her B.Sc.(Hons.) degree in civil and environmental engineering from University of Ruhuna (Sri Lanka) in 2009. Currently, she is a PhD student in City University of Hong Kong SAR, China. Her research interests include air pollution controlling methodologies and numerical simulations of gas-solid flows. Ms. Sakura is an associate member of Institute of Engineers, Sri Lanka. She has been rewarded second place in Young Engineer Section, 2010 from Institute of Engineers, Sri Lanka, for her undergraduate final year project.

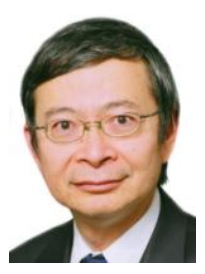

Andrew Y. T. Leung taught in HKU and Manchester U and is now associating with City University as the chair of Sustainable Construction. He is an honorary/guest professor of 15 universities internationally. He published more than 1050 pieces of work in Built Environmen including 12 monographs and 500 journal papers of which 450 are cited in Science Citation Index. He is the president of Asian Institute of Intelligent Buildings, the vice-chairman of the Chinese Green Building Council (Hong Kong), a member of The Royal Institute of Chartered Surveyors HK Board, the Join Structural Division Committee HKIE \& IStructE, and HK BEAM Faculty. $\mathrm{He}$ is also a member of the HK BEAM Society IA group and of the HKGBC IMC group. 